\title{
The effect of coarse aggregate on the mode of failure of concrete in compression and flexure*
}

by R. Jones, B.Sc., Ph.D.

and M. F. Kaplan, Ph.D., B.Sc.(Eng.), B.A., B.Com., A.M.I.Struct.E., A.M.(S.A.).I.C.E.

Contribution by F. A. Blakey, B.E.(Hons.), Ph.D. (Division of Building Research, Commonwealth Scientific and Industrial Research Organization)

The paper by Dr Jones and Dr Kaplan has been read with considerable interest. It is an important contribution to the understanding of the interaction of aggregate and matrix and the resulting effect on the properties of concrete.

The problem is being studied at the Division of Building Research in Australia, but at this stage it is difficuit to compare results because the authors used saturated specimens, following standard testing procedure, whilst the writer has used air-dried specimens in the hope of approaching a little closer to practical conditions.

The authors have shown that pre-failure cracks in compression specimens form at a lower percentage of the ultimate load for concretes containing fairly smooth siliceous aggregate than for concretes containing more angular stone. They suggest that the pre-failure cracks are failures of adhesion between mortar and coarse aggregate, and that the adhesion is less for the smoother material. The writer has recently presented a very simplified analysis ${ }^{11}$ of the stress distribution within concrete, between aggregate and matrix, and endeavoured to define the conditions under which cracking of concrete would begin either in the cement paste, the bond between paste and aggregate, or within the aggregate itself. Although no very definite conclusions were reached, it appeared from this analysis that the most likely form of cracking, when shrinkage stresses could be ignored, was failure of adhesion or bond. The work of Farran ${ }^{(2)}$ is of interest in relation to the importance of this bond between aggregate and cement. He has shown that a good bond may be expected between cement and calcareous aggregates because of epitaxial growth in the cement of crystals of calcium hydroxide or carbonate out from the calcium carbonate in the aggregate. This may be relevant to the results obtained by the authors for concrete with aggregate $F$.

The authors have considered concrete as composed of two phases, coarse aggregate and mortar. This is an idealization frequently made, with justification, but it might be more logical to make the division between cement paste and all aggregate. The adhesion must be between cement paste and coarse aggregate but, if this bond is likely to fail for smooth siliceous coarse aggre-

\footnotetext{
* Pages 89-94.
}

gate, it seems likely that it would also fail for smooth siliceous fine aggregate or sand, although the cracks formed in the latter case may be too small to detect by the pulse technique.

In Figure 2, the authors have shown the relation between flexural strength and the compressive stress at which pre-failure cracks form. The ratio of the flexural strength to compressive stress ranges from about 0.2 to 0.125 . This is roughly the range of Poisson's ratio for concrete and the results can be taken to show that the ultimate tensile strain in flexure is equal to the transverse tensile strain at which cracks form in compression specimens. This point has been noted in earlier work by Blakey and Beresford (3).

It is implicit in the results presented by the authors that there was no evidence of cracking in flexure before the ultinate load was reached. The writer has found such evidence $^{(3)}$, but the analysis mentioned earlier(1) shows that the relative properties of aggregate and matrix will determine whether or not pre-failure cracks form in tension and that frequently failure may be instantaneous.

The work at present being done by the writer and others is concerned with the relation between set cement paste and sant in mortar which is allowed to dry normally in air at $70^{\circ} \mathrm{F}$ and 50 or $65^{\circ} \mathrm{o}$, relative humidity without any period of water curing. From this study it appears that the stresses set up in the cement paste as it shrinks around the aggregate will cause cracking of the paste, usually within ten days. A theoretical analysis which has been made suggests that this behaviour will hold not only for the mortars studied but for all normal concretes in similar conditions. In support of this prediction it has been noted that both the modulus of rupture (Figure I) and sonic modulus of elasticity (Figure II) of the mortars reach a maximum at an early age, then decrease, and subsequently rise again.

The hypothesis proposed is that the decrease in both these quantities is caused by the formation of shrinkage micro-cracks in the cement paste, and that the subsequent recovery is due to the action of atmospheric carbon dioxide or other forms of autogenous healing. If this hypothesis is valid, then with air-dried concrete it may be possible that pre-failure cracks could result not from the failure of the adhesion between paste and aggregate, but from the re-opening of the shrinkage micro-cracks, which may be expected to be weaker than the rest of the cement paste. The existence of such shrinkage cracks in the cement paste had been predicted by Carlson. ${ }^{(4)}$ 


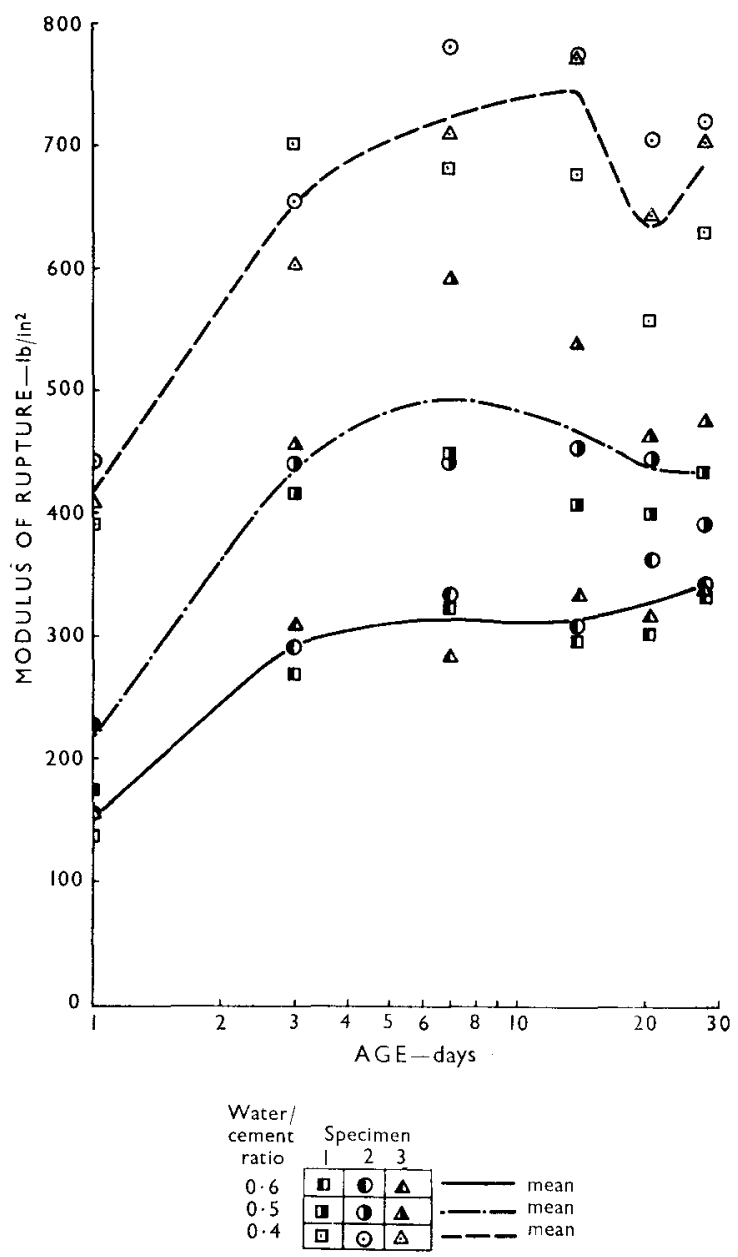

Figure I: Relation between modulus of rupture and age of mortars.

Contribution by Professor Henry J. Cowan

(Department of Architectural Science, University of Sydney)

Dr Jones was one of the first to demonstrate, in 1951, that cracking occurred in compression specimens at relatively low loads, and that this did not lead to immediate fracture of the specimen. The present paper provides further valuable experimental data, and thus makes a notable contribution towards the development of a theory for the mechanism of the failure of concrete.

I would like to draw attention to the work of Rehbinder et alia, which has been translated by the C.S.I.R.O. ${ }^{15}$ This shows that the penetration of a liquid into a very fine crack in a natural stone greatly lowers the strength of the material. It would seem that molecular attractions, which are destroyed by the liquid film, can act across micro-cracks and this would explain the existence of

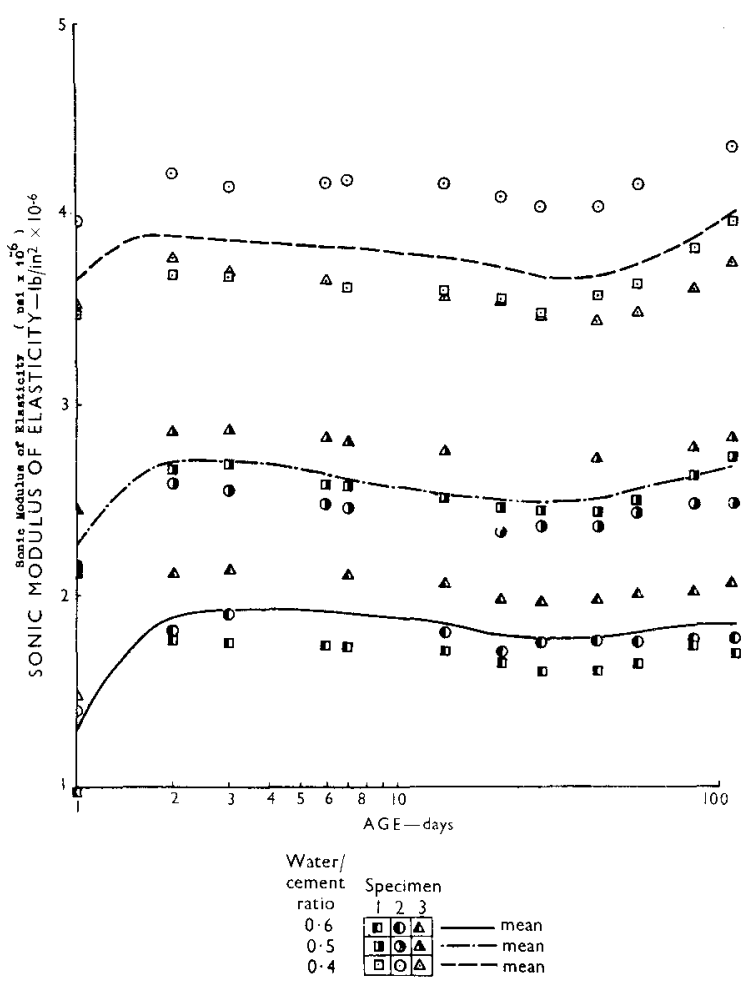

Figure II: Relation between sonic modulus of elasticity and age of mortars.

stable cracks of the type observed by Dr Jones and Dr Kaplan.

The existence of stable micro-cracks at relatively low loads also serves to explain the high inelastic strains observed in concrete. The observed ultimate concrete strains in a short-duration test are much too high to be explicable in terms of creep, and the conventional viscoelastic model is therefore inadequate. Moreover, this model does not produce the declining portion of the stress-strain diagram commonly observed in compression tests carried out at a constant rate of strain.

The writer has therefore suggested a model embodying a series of brittle springs to represent the stable microcracks $^{(6)}$ (Figure III). The springs are elastic until they fracture at the limiting strain corresponding to the formation of the micro-crack. This does not immediately result in failure of the concrete; however, as the number of springs is reduced, the remaining springs each carry a greater share of the load, and the deformation is increased accordingly. The resulting load-deformation curve is shown in Figure IV.

The writer therefore considers that Dr Jones's work will eventually contribute to the theory of the inelastic deformation of concrete, as well as to the theory of its ultimate strength. 


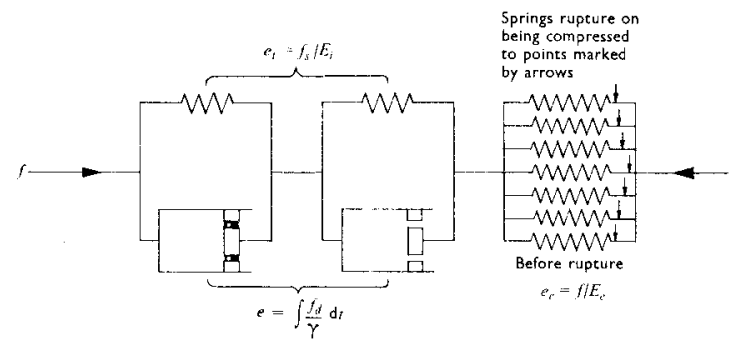

Figure III: Comprehensive mechanical model for the elastic and inelastic deformation of concrete $(E=$ modulus of elasticity, $\gamma=$ viscosity of dashpots, $t=$ time). Before rupture $e_{e}=f / E_{e}$. Springs rupture on being compressed to points marked by arrows.

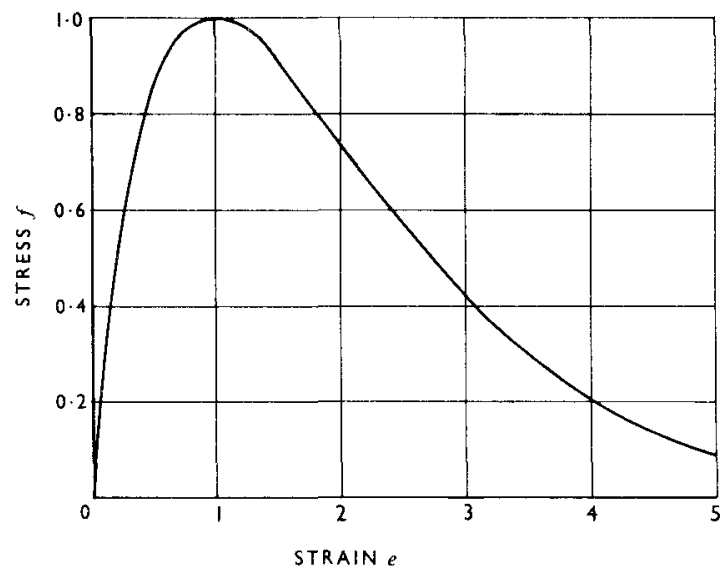

Figure IV: Load-deformation curve produced by the model shown in Figure III when it is deformed rapidly enough to produce negligible viscous deformation. (Expressed in terms of the maximum stress and strain.)

\section{Reply by the authors}

The authors were very pleased to receive the contributions from Dr Blakey and Professor Cowan, both of whom have made notable contributions to the study of the failure and fracture of concrete.

The recent article by Dr Blakey (1) was not available until after the authors had submitted their manuscript, but it has since been read with great interest. The authors agree with Dr Blakey that cracks may also begin at interfaces between sand and cement paste as well as at the boundaries of the coarse aggregate. Indeed it could be inferred from the authors' results that cracks are initiated at these interfaces for those concretes with flexural strengths equal to the flexural strength of the comparable mortar and at the interfaces between coarse aggregate and mortar for those concretes with lower flexural strengths than the comparable mortars.
The present article was based on a much fuller discussion given in an unpublished paper ${ }^{(7)}$. To concentrate attention on the main results, the discussion of pre-cracking in flexure contained in the original note was omitted. The authors are well aware of the excellent work by Dr Blakey and $\mathrm{Mr}$ Beresford ${ }^{(3)}$ in this field and their results, among others, were quoted to suggest that the micro-cracks in flexure start at about $70 \%$ of the flexural strength: it is not known whether this value is influenced appreciably by the type of aggregate. Assuming the value of $70 \%$ in all cases, from Figure 2 of their paper the authors have deduced ${ }^{(7)}$ that the static Poisson's ratio would range from 0.11 for the richer mixes to 0.21 for the leaner mixes.

Thie results given by Dr Blakey for air-cured concrete are of great interest. Chefdeville ${ }^{(8)}$ has shown that if aircured concrete is subsequently saturated with water, the dynamic modulus increases but never attains such a high value as that given by comparable concrete cured continuously in water: the presence of unhealed shrinkage cracks would explain this observation. Dr Blakey's conclusion that the re-opening of shrinkage cracks in the cement paste can precede bond failures between the paste and the aggregate has obvious practical implications, and it is to be hoped that his observations will stimulate further work on the failure of concrete under different curing conditions.

Professor Cowan's comments on the stability of microcracks in natural rock are of interest but do not explain fully the behaviour of concrete. For example, in the case of concrete in flexure, soaking a dry specimen in water produces an increase in the flexural strength possibly because of the healing of shrinkage micro-cracks as suggested by Dr Blakey. It may be that the more heterogeneous nature of concrete complicates the conditions for crack propagation and that a micro-crack becomes stable when its tip encounters a region of stronger material.

The model suggested by Professor Cowan to take into account the formation of micro-cracks in concrete represents a considerable advance on the purely visco-elastic model. It would seem to be capable of explaining the steeper slope of the stress-strain curve during the unloading of a compression specimen in the measurement of the static Young's modulus. However, it would be necessary to allow some of the springs to re-form in order to correlate with subsequent loading cycles.

\section{REFERENCES}

1. BLAKEY, F. A. Some considerations of the cracking or fracture of concrete. Civil Engineering and Public Works Review. Vol. 52, No. 615. September 1957. pp. 1000-1003.

2. FARRAN, J. Contribution minéralogique à l'étude de l'adhérence entre les constituants hydratés des ciments et les matériaux enrobés. Revue des Matériaux de Construction et de Travaux Publics (Edition C). No. 490-491. July-August 1956. pp. 155-172. No. 492. September 1956. pp. 191-209. 
3. BLAKEY, F. A. and BERESFORD, F. D. Tensile strains in concrete. Melbournc, Commonwealth Scientific and Industrial Research Organization, Division of Building Research. Part I. 1953. pp. 69. Report C2.2-1. Part II. 1955. pp. 52. Report C2.2-2.

4. CARLSON, R. W. Remarks on durability of concrete. Journal of the American Concrete Institute. Vol. 10 , No. 5. April 1939. pp. 359-364.

5. REHBINDER, P. A., SCHREINER, L. A. and ZHiGaCH, K. F, Hardness reducers in drilling. Translated from the Russian book by the Council for Scientific and Industrial Research, Melbourne. 1948. pp. 163.
6. COWAN, H. J. Representation of the inelastic deformation of concrete by means of a mechanical model. Nature. Vol. 178, No. 4527. 4th August 1956. pp. 278-279.

7. ROAD RESEARCH LABORATORY. The effect of stone on the mode of failure of concrete in compression and Hexure. Department of Scientific and Industrial Research, Road Research Laboratory Note No. RN/2693/RJ.MFK, Harmondsworth, 1956. (Unpublished.)

8. Cherdeville, J. Vibration testing of concrete. Part 2. Application of the method toward estimating the quality of concrete. RILEM Bulletin No. 15. 1953. pp. $61-77$. 